\title{
Digestion of carbohydrates of hay in small ruminants
}

\author{
BY P. PORTER* AND A. G. SINGLETON \\ Physiology Department, University of Liverpool \\ (Received 24 August 1970-Accepted I6 November 1970)
}

\begin{abstract}
I. An analytical scheme for the separation and identification of carbohydrates in food, duodenal contents and faeces of sheep is described.

2. This scheme was applied to three sheep and one goat given hay diets, and the quantities of carbohydrates disappearing from the rumen and intestine respectively were assessed by reference to faecal lignin. Results indicated that $95-100 \%$ of digestible cellulose and $96-99 \%$ of digestible pentosan disappeared from the rumen.

3. In an investigation of the microbial fraction of duodenal contents in the goat it was estimated that approximately $6 \mathrm{~g}$ carbohydrate passed to the duodenum per $24 \mathrm{~h}$. Glucose accounted for a little over half of this amount.
\end{abstract}

The dietary carbohydrate available to the ruminant is degraded by the microorganisms in the forestomach to produce short-chain fatty acids which supply much of the dietary energy. Investigation of the composition of digesta indicates that only well-digested material leaves the rumen (Paloheimo, Mäkelä \& Salo, 1955; Gray, Pilgrim \& Weller, I958) and apparently very little dietary starch passes through the abomasum (Weller \& Gray, 1954). These observations find support in that only small differences in sugar levels have been demonstrated between portal and arterial blood (Schambye, 1951 ; Annison, Hill \& Lewis, 1957).

Alongside their activities in the degradation of carbohydrates, the micro-organisms of the rumen are known to synthesize and store a polysaccharide, glucan (Baker, 1943; Oxford, I95I; Masson \& Oxford, 195I). The studies of Heald (195I) suggest that this microbial polysaccharide may have little or no nutritional significance to the ruminant since it was calculated that only about $5 \mathrm{~g} / \mathrm{d}$ of this component entered the abomasum of sheep receiving a hay diet.

However, Ridges \& Singleton (1962) estimated from measurements of flow of constituents through the duodenum of goats fed on hay and concentrates that $70 \mathrm{~g}$ of a crude fraction, designated 'total soluble carbohydrate by difference', disappeared from the intestines. This crude fraction will include hemicelluloses, pectins, oligosaccharides, and such like which are either soluble in hot dilute alkali or hydrolysed by dilute acid. Hemicelluloses are quantitatively an important source of dietary energy to the ruminant, but the extent to which fibre carbohydrates other than cellulose are digested in the rumen has received little attention.

The possible significance of carbohydrate digestion in the intestines of the ruminant is a subject which has recently received more precise study (Topps, Kay \& Goodall, I968; MacRae \& Armstrong, 1969). The present paper describes quantitative studies

* Present address: Unilever Research Laboratory, Colworth House, Bedford. 
of the digestion of the carbohydrates of hay in the rumen and intestines of three sheep and a goat with re-entrant duodenal cannulas. These findings have been the subject of preliminary communications (Porter \& Singleton 1965, 1966).

\section{METHODS}

\section{Collection and preparation of samples for analysis}

Re-entrant duodenal fistulas were prepared in an adult cross-bred goat and in three adult Clun Forest cross-bred sheep as described by Singleton (196r). The animals were given their respective diets twice daily at 08.30 and $\mathrm{r} 6.30$ hours, and were maintained in metabolism cages. The experiments were done at a time after the operation when food intake and faeces output had reached pre-operative levels.

Faeces were collected and weighed over a period of $10 \mathrm{~d}$, and representative $100 \mathrm{~g}$ samples from each day were freeze-dried, desiccated, weighed to dryness to assess the total dry-matter excretion and finely milled without loss in a sealed grinder. Hay samples were chopped, ground in a hammer mill and finely ground in the sealed grinder. The chopped samples were desiccated and weighed to dryness to assess dry-matter intake.

In three experiments investigating the total digestion of carbohydrates, samples of approximately $200 \mathrm{ml}$ duodenal contents were taken on eight occasions at $9 \mathrm{~h}$ intervals so that samples of digesta were obtained for each successive $3 \mathrm{~h}$ period of the day. Each sample was freeze-dried, desiccated, weighed to dryness, and finely milled in the sealed grinder.

In an experiment concerned with microbial polysaccharide, samples of approximately $100 \mathrm{ml}$ duodenal contents were taken at $3 \mathrm{~h}$ intervals for $3 \mathrm{~d}$ so that samples of digesta were obtained for each hour of the day. The samples were separated into supernatant fluid, micro-organisms and fibre by filtering and centrifuging as follows. The digesta were strained through six layers of surgical gauze and the filtrate was collected in a flask. The solid retained in the gauze was washed off with water and stirred vigorously for to min to aid the release of micro-organisms from the fibre residues, and filtered through a gauze pad. The filtrates were combined and filtered again through fine muslin to remove fine fibre particles which had passed the surgical gauze.

The filtrate was centrifuged at $20000 \mathrm{~g}$ for $20 \mathrm{~min}$ in a refrigerated centrifuge. The residues were washed with distilled water with further centrifugation, and the washings were added to the supernatant fluid. The solid residue was freeze-dried from suspension in distilled water. The supernatant fluids and washings were concentrated to $50 \mathrm{ml}$ vol. by evaporation under reduced pressure at $60^{\circ}$. The fibre residues were washed from the filter pads, dried over silica gel, weighed to dryness and ground in the sealed grinder. 


\section{Quantitative estimation of sugars}

The aniline trichloroacetic acid reagent of Gardell (I95I) was used to estimate reducing sugars in alcholic solutions. The reactions with hexoses and pentoses result in an absorption spectrum with $\lambda \max$ at $370 \mathrm{~nm}$. The colour reaction was affected by the proportion of water in solution, so standard curves were established using 9: $\mathrm{I}, \mathrm{n}$-butanol-water, since this was the eluting solvent used in column and paper chromatography.

\section{Hydrolysis of polysaccharides}

The polysaccharides were hydrolysed by refluxing at $100^{\circ}$ in $\mathrm{r} \cdot 5 \mathrm{~N}-\mathrm{H}_{2} \mathrm{SO}_{4}$ for $3 \mathrm{~h}$ with continuous stirring. A preliminary quantitative check of the effect of this treatment on monosaccharides indicated a progressive decomposition of sugars after a period of $4 \mathrm{~h}$. After hydrolysis, the solution was filtered, cooled in an ice-bath and neutralized with $6 \mathrm{~N}-\mathrm{NaOH}$. The solution was desalted electrolytically, freeze-dried in ampoules and sealed under nitrogen.

\section{Quantitative chromatographic separation of sugar on heated cellulose columns}

Cellulose powder (Whatman standard grade) was stirred into a fine suspension in 9: $\mathrm{I}, \mathrm{n}$-butanol- $\mathrm{H}_{2} \mathrm{O}$, and packed in four stages into a glass column $(60 \times \mathrm{I} \mathrm{cm})$. Each successive portion of the column was compacted after the cellulose had settled under normal solvent flow by application of $7 \mathrm{lb} / \mathrm{in}^{2}$ pressure from a nitrogen cylinder.

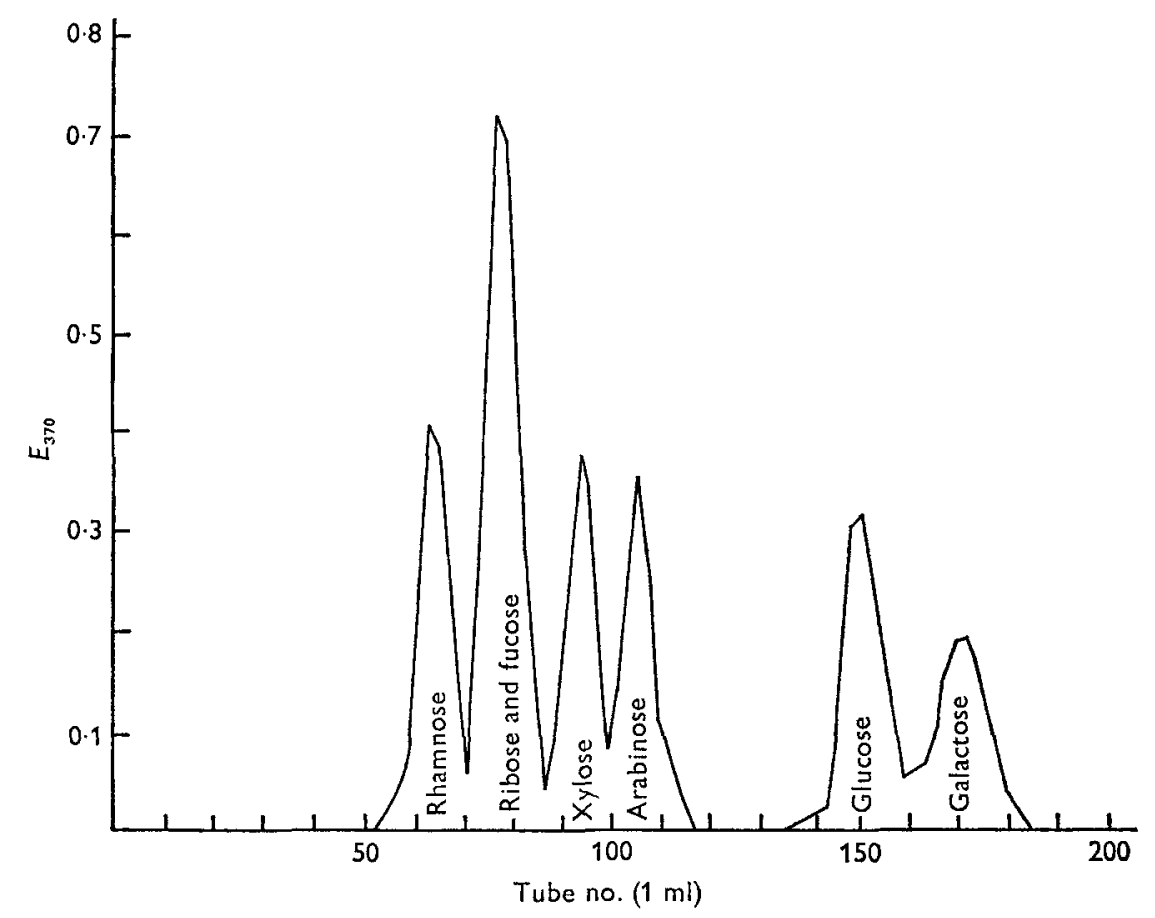

Fig. I. Separation of monosaccharides by chromatography on cellulose columns. 
The packing of the column was visually checked by the passage of bromophenol blue. Monosaccharides were separated chromatographically by applying the sugars to the top of the column in $0.5 \mathrm{ml}$ distilled water, and the eluate was collected using a $\mathrm{I} \mathrm{ml}$ siphon fraction collector. Quantitative recovery of monosaccharides in the column eluates was established by the colorimetric techniques. The elution characteristics of the column were established with standard sugars (Fig. $\mathrm{x}$ ). The sugars in the elution peaks were also recovered by evaporation of eluates under reduced pressure and identified against standards by paper chromatography.

\section{Quantitative chromatographic separation of sugars on paper}

The column chromatographic technique was too slow a procedure to deal with a large number of determinations. It was therefore used almost exclusively for the determination of monosaccharides in the hydrolysates of microbial fractions of duodenal contents. A paper chromatographic technique was adapted for quantitative estimation of monosaccharides.

Sugars were separated by chromatography on Whatman no. 4 filter paper using n-butanol-ethanol-water, $7: 2: 2$, as solvent and a descending flow for a period of $\mathrm{I} 8 \mathrm{~h}$. Chromatograms were run in triplicate and subsequently divided into three strips. The centre strip was sprayed with ammoniacal silver nitrate to detect the spots, and measurements were taken of distances travelled and size of spots. The two outer chromatograms were then cut into sections which were eluted with $3 \mathrm{ml}$ of ethanolwater, 9: $\mathrm{I}$, at $56^{\circ}$ with constant shaking for $2 \mathrm{~h}$ in glass tubes $(7.5 \times \mathrm{I} \mathrm{cm})$ sealed with silicone rubber stoppers. The monosaccharide in I $\mathrm{ml}$ of eluate was quantitatively assessed by the colorimetric technique using aniline trichloroacetic acid reagent. Blanks for spectrophotometry were prepared by eluting sections of each chromatogram which contained no sugar. Quantitative reference curves of a range of concentrations of each sugar were constructed by chromatography, followed by elution and colorimetry.

\section{Extraction and estimation of carbohydrate fractions and lignin}

In brief, the procedure for extraction divided the carbohydrates into groups as follows.

(a) $80 \%$ ethanol extract: mono-, di-, tri- and oligo-saccharides;

(b) Water at $80^{\circ}$ : 'pectins' and fructosan;

(c) $\mathrm{r} \cdot 5 \mathrm{~N}-\mathrm{H}_{2} \mathrm{SO}_{4}$ at $100^{\circ}$ : hemicellulose;

(d) $72 \% \mathrm{H}_{2} \mathrm{SO}_{4}$ : cellulose and lignin.

The carbohydrate other than fructosan in the water-soluble fraction has been termed 'pectin' in order to provide a brief reference name for the fraction in the text. The composition of the fraction is quite different from true pectin, which does not contain glucose.

Approximately $500 \mathrm{mg}$ of sample was extracted for $4 \mathrm{~h}$ with benzene-ethanol, $\mathrm{I}: 2$, in a Soxhlet apparatus. The residue was then extracted with $80 \%$ ethanol in the Soxhlet for 3-4 h. The extract was concentrated under reduced pressure to a final volume of $3-5 \mathrm{ml}$, and the carbohydrates were hydrolysed in $\mathrm{r} \cdot 5 \mathrm{~N}-\mathrm{H}_{2} \mathrm{SO}_{4}$ at $100^{\circ}$ 
for $3 \mathrm{~h}$. The solution was cooled in an ice-bath, neutralized, made up to ro $\mathrm{ml}$ vol., desalted electrolytically, freeze-dried in $2 \mathrm{ml}$ vol. and stored in sealed ampoules under nitrogen.

The residue from the $80 \%$ ethanol extract was treated with $50-100 \mathrm{ml}$ distilled water at $80^{\circ}$ for $2 \mathrm{~h}$ with continuous stirring. The supernatant fluid was concentrated under reduced pressure to $25 \mathrm{ml}$ vol.; $20 \mathrm{ml}$ were taken for estimation of carbohydrates as described above, and $5 \mathrm{ml}$ for fructosan determination. Fructosan was determined as fructose after hydrolysis with $I \%$ oxalic acid at $80^{\circ}$ for $10 \mathrm{~min}$, using the colorimetric alcoholic resorcinol reagent of Arni \& Percival (1951).

Hemicelluloses were determined in the fibre remaining after aqueous extraction, by hydrolysis for $3 \mathrm{~h}$ at $100^{\circ}$ in $15 \mathrm{ml} \mathrm{I} \cdot 5 \mathrm{~N}-\mathrm{H}_{2} \mathrm{SO}_{4}$. The supernatant fluid was replaced with a further Io $\mathrm{ml} \times \cdot 5 \mathrm{~N}-\mathrm{H}_{2} \mathrm{SO}_{4}$, and the hydrolysis of the fibre residue was continued for a further $3 \mathrm{~h}$. The supernatant fluids were then pooled, neutralized and made to $50 \mathrm{ml}$ vol., desalted and freeze-dried in $2 \mathrm{ml}$ vol. for quantitative estimation of sugars.

For the determination of cellulose the fibre residue from acid hydrolysis was washed with ethanol and then with ether, desiccated and weighed to dryness. The dry fibre was treated with ice-cold $72 \% \mathrm{H}_{2} \mathrm{SO}_{4}$ in sinter crucibles for $4 \mathrm{~h}$, and the residue was washed on the filter with hot distilled water, desiccated and weighed to dryness. Cellulose was estimated as the quantity removed in the $72 \% \mathrm{H}_{2} \mathrm{SO}_{4}$ digest. The residue was ashed by heating in a muffle furnace at $500^{\circ}$ for $16 \mathrm{~h}$, and lignin was estimated as the loss in weight.

Detailed chemical studies of lignin and its use in quantitative aspects of ruminant digestion have been described previously (Porter \& Singleton 1971).

\section{Rhamnose as a marker for quantitative recovery of monosaccharides}

The processes involved in the analyses for carbohydrate involve extraction, hydrolysis, neutralization, electrolytic desalting, freeze-drying and chromatography. The loss due to poor recovery in one or all of these steps could therefore be considerable, and it was necessary to use a marker for estimation of recovery. Rhamnose was a satisfactory marker since it was barely detectable in any of the hydrolysates except the microbial carbohydrate fraction. A known quantity was added at each stage before hydrolysis and the ease of its chromatographic separation (Fig. I) facilitated accurate recovery from mixtures of monosaccharides.

\section{RESULTS}

\section{Digestion of structural and non-structural carbohydrates of hay}

Studies of carbohydrate digestion were conducted in three sheep each receiving a different hay. The food intake, faecal output and digestibility of carbohydrate fractions are shown in Table $I$ and compared with values for dry matter and organic matter.

The importance of hemicellulose as a dietary constituent for ruminants on hay diets is apparent from the fact that it accounted for approximately one-third of the 


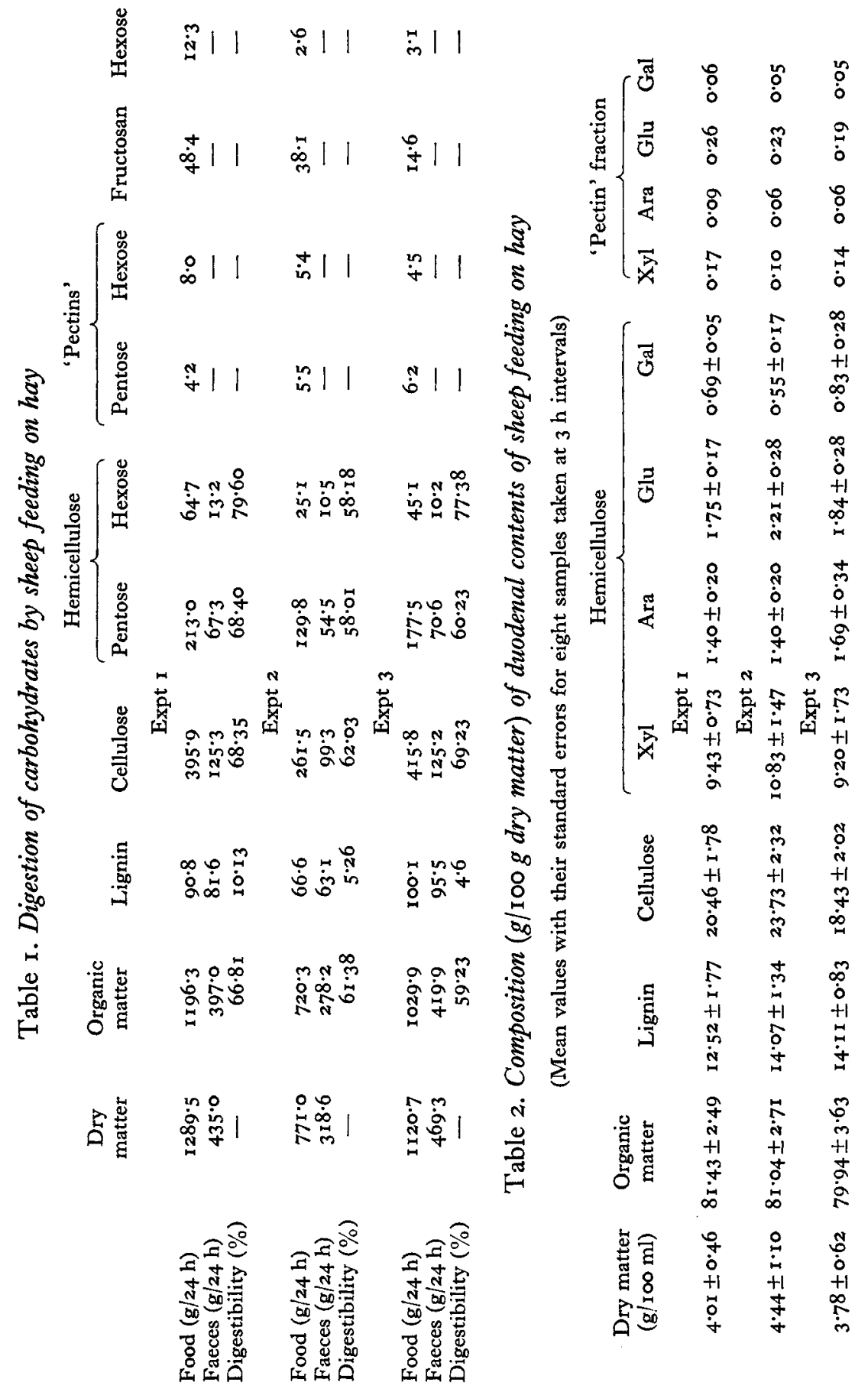


structural carbohydrate of hay and more than $20 \%$ of the organic matter. The digestibility of the pentosan component was closely similar to that of cellulose and it accounted for $17-18.2 \%$ of the digested organic matter in the three experiments. In two of the experiments the digestibility of the hexose component of the hemicellulose fraction was considerably in excess of the pentose component and amounted to 34.9 and $5{ }^{1 \cdot 5} \mathrm{~g}$ of digested hexose, mainly as glucose.

The hydrolysate of the hemicellulose of hay normally includes some glucose and galactose. However, the high digestibility of the hexose component of the hemicellulose fraction was probably due to the inclusion of a poorly soluble starch in the fraction and, in view of the amount, it is important to assess how much of this component is made available for digestion in the intestines.

The non-structural carbohydrates of hay, the pectins, fructosan and hexose sugars, in total accounted for between 2 and $6 \%$ of the organic matter. This supplied between 28 and $73 \mathrm{~g}$ of digestible carbohydrate in the three experiments with sheep (Table 2 ).

\section{Passage of carbohydrates into the duodenum and quantitative assessment of digestion in the intestines}

The carbohydrate content of duodenal samples is shown in Table 2 for three experiments with sheep. The concentration of soluble carbohydrate was very low and confined to the 'pectin' fraction. The composition of the 'pectin' hydrolysate of duodenal contents was quite different from that of the hay. Arabinose was a major product of the hydrolysis of hay pectin fraction together with glucose, whereas in the duodenal content arabinose was a minor component only.

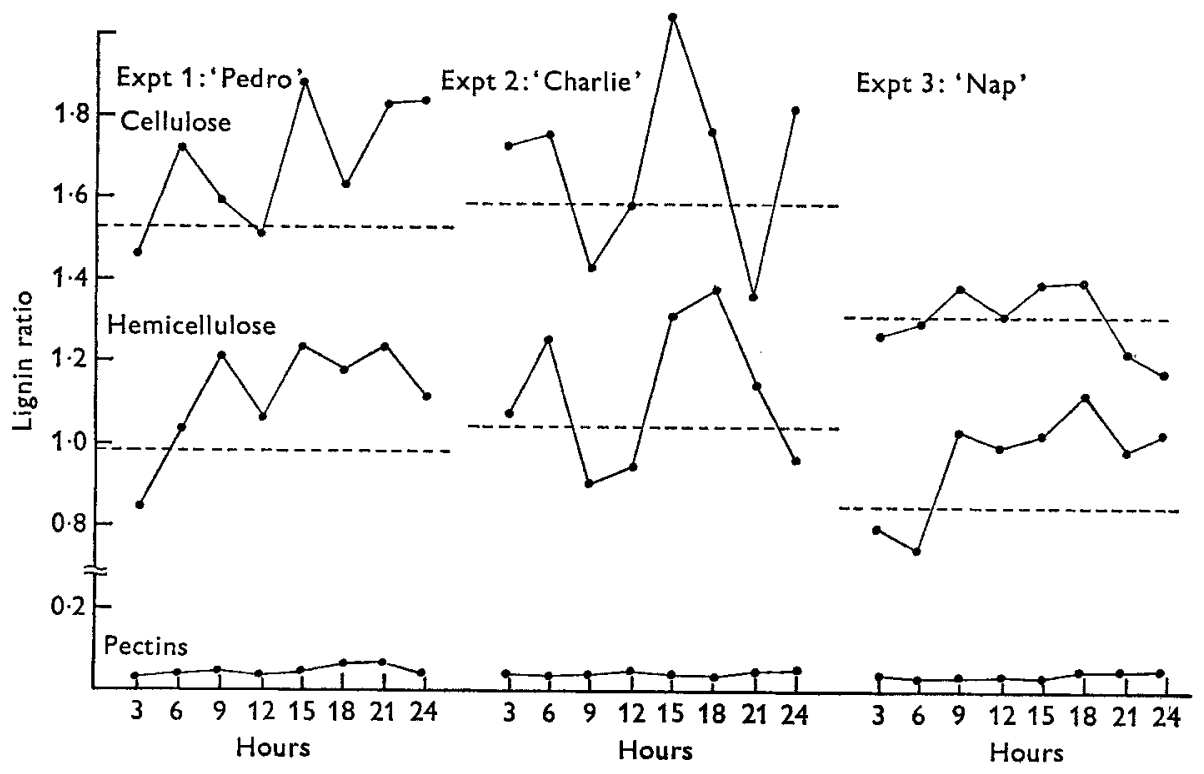

Fig. 2. Variations in lignin ratios of carbohydrates in the duodenal contents of three sheep. The faecal lignin ratios for cellulose and hemicellulose are shown as broken lines in each experiment. 
The values for hemicellulose and cellulose in the duodenum were lower than in the faeces. This is partly a result of the high ash content in freeze-dried material from the duodenum. Evidence for the digestion of these components may only be obtained from measurement of total quantities passing through the duodenum or by comparison of the ratio to lignin in the duodenum and in the faeces.

Table 3. Estimation of quantities of carbohydrates passing through the duodenum and amounts disappearing from stomach and intestines in sheep feeding on hay

(The amounts were estimated from the carbohydrate: lignin ratio and faecal lignin excretion)

\begin{tabular}{|c|c|c|c|c|c|}
\hline Constituent & $\begin{array}{l}\text { Amount } \\
\text { passing into } \\
\text { duodenum } \\
(\mathrm{g} / 24 \mathrm{~h})\end{array}$ & $\begin{array}{l}\text { Percentage } \\
\text { of amount } \\
\text { eaten } \\
\text { Expt } x\end{array}$ & $\begin{array}{c}\text { Amount } \\
\text { digested in } \\
\text { in stomach } \\
(\mathrm{g} / 24 \mathrm{~h})\end{array}$ & $\begin{array}{c}\text { Percentage } \\
\text { of total } \\
\text { digested }\end{array}$ & $\begin{array}{l}\text { Amount } \\
\text { digested in } \\
\text { intestines } \\
(\mathrm{g} / 24 \mathrm{~h})\end{array}$ \\
\hline Organic matter & 530.8 & $54 \cdot 4$ & $665 \cdot 5$ & $83 \cdot 3$ & 133.8 \\
\hline Cellulose & 133.4 & $33 \cdot 7$ & $262 \cdot 5$ & $97 \cdot 0$ & $8 \cdot 1$ \\
\hline Hemicell $\left\{\begin{array}{l}\text { Pentose } \\
\text { Hexose }\end{array}\right.$ & $\begin{array}{l}70 \cdot 6 \\
15 \cdot 9\end{array}$ & $\begin{array}{l}33 \cdot 2 \\
24 \cdot 6\end{array}$ & $\begin{array}{r}142.4 \\
48.8\end{array}$ & $\begin{array}{l}97 \cdot 7 \\
94 \cdot 7\end{array}$ & $\begin{array}{l}3 \cdot 3 \\
2 \cdot 7\end{array}$ \\
\hline 'Pectin' $\left\{\begin{array}{l}\text { Pentose } \\
\text { I Iexose }\end{array}\right.$ & $\begin{array}{l}x \cdot 7 \\
2 \cdot 1\end{array}$ & $\begin{array}{l}40 \cdot 5 \\
26 \cdot 3\end{array}$ & $\begin{array}{l}2 \cdot 5 \\
5 \cdot 9\end{array}$ & $\begin{array}{l}59 \cdot 5 \\
73 \cdot 8\end{array}$ & $\begin{array}{l}1 \cdot 7 \\
2 \cdot 1\end{array}$ \\
\hline & & Expt 2 & & & \\
\hline Organic matter & $363 \cdot 3$ & $50 \cdot 44$ & $357^{\circ} 0$ & $80 \cdot 8$ & $85 \cdot 1$ \\
\hline Cellulose & 106.4 & 40.7 & $155^{\circ} 1$ & $95^{\circ} 6$ & $7 \cdot 1$ \\
\hline Hemicell $\left\{\begin{array}{l}\text { Pentose } \\
\text { Hexose }\end{array}\right.$ & $\begin{array}{l}54 \cdot 8 \\
12 \cdot 4\end{array}$ & $\begin{array}{l}42 \cdot 2 \\
49 \cdot 4\end{array}$ & $\begin{array}{l}75 \cdot 0 \\
12 \cdot 7\end{array}$ & $\begin{array}{l}99 \cdot 6 \\
87 \cdot 0\end{array}$ & $\begin{array}{l}0.3 \\
x \cdot 9\end{array}$ \\
\hline 'Pectin' $\left\{\begin{array}{l}\text { Pentose } \\
\text { Hexose }\end{array}\right.$ & $\begin{array}{l}0 \cdot 7 \\
1 \cdot 3\end{array}$ & $\begin{array}{l}12 \cdot 8 \\
24 \cdot 1\end{array}$ & $\begin{array}{l}4^{\cdot 8} \\
4^{\cdot 1}\end{array}$ & $\begin{array}{l}87 \cdot 3 \\
75 \cdot 9\end{array}$ & $\begin{array}{l}0 \cdot 7 \\
\mathrm{I} \cdot 3\end{array}$ \\
\hline & & Expt 3 & & & \\
\hline Organic matter & 540.8 & $52 \cdot 6$ & $489 \cdot x$ & $80 \cdot 2$ & 120.9 \\
\hline Cellulose & $124 \cdot 7$ & $30 \cdot 0$ & $29 I \cdot I$ & 100 & $\circ$ \\
\hline Hemicell $\left\{\begin{array}{l}\text { Pentose } \\
\text { Hexose }\end{array}\right.$ & $\begin{array}{l}73 \cdot 7 \\
18 \cdot 1\end{array}$ & $\begin{array}{l}4 I \cdot 5 \\
40 \cdot 1\end{array}$ & $\begin{array}{r}103 \cdot 8 \\
27 \cdot 0\end{array}$ & $\begin{array}{l}97 \cdot 1 \\
77 \cdot 4\end{array}$ & $\begin{array}{l}3 \cdot 1 \\
7 \cdot 9\end{array}$ \\
\hline 'Pectin' $\left\{\begin{array}{l}\text { Pentose } \\
\text { Hexose }\end{array}\right.$ & $\begin{array}{l}r \cdot 3 \\
1 \cdot 7\end{array}$ & $\begin{array}{l}20 \cdot 9 \\
38 \cdot 7\end{array}$ & $\begin{array}{l}4 \cdot 9 \\
3 \cdot 3\end{array}$ & $\begin{array}{l}79 \cdot 0 \\
73 \cdot 3\end{array}$ & $\begin{array}{l}1 \cdot 3 \\
1 \cdot 7\end{array}$ \\
\hline
\end{tabular}

The variations in lignin ratios at $3 \mathrm{~h}$ intervals are presented in Fig. 2 for cellulose, hemicellulose and 'pectins' in the three experiments. There was no consistent pattern for the three animals related to feeding or time of day, but for each animal the pattern of change for hemicellulose was very similar to that for cellulose. In two of the sheep (Expts $I$ and 3 ) the lignin ratios for hemicellulose exceeded the faecal value at all times except in the early hours of the morning. This suggests that some hemicellulose is digested in the intestines, and clearly the same argument applies to cellulose in Expt $\mathrm{r}$.

An assessment of total quantities of any component passing into the duodenum in $24 \mathrm{~h}$ may be obtained from lignin ratios by reference to total quantity of lignin excreted in the faeces in $24 \mathrm{~h}$, assuming this to be the quantity which passes the duodenum. The mean value of lignin ratios (Fig. 2) takes into account the periodic 
variation throughout $24 \mathrm{~h}$ and is used to calculate the total quantities of carbohydrates passing into the duodenum (Table 3 ). Thus, from the $24 \mathrm{~h}$ quantities of food intake and faecal output (Table 2), calculations may be made of quantities disappearing in the stomachs and intestines respectively.

The amount of carbohydrate in the 'pectin' fraction calculated to pass into the duodenum ranged from 2.0 to $3.8 \mathrm{~g}$ and supplied less than $2.0 \mathrm{~g}$ glucose $/ 24 \mathrm{~h}$ for intestinal hydrolysis. The hemicellulose fraction supplied between 12.4 and $18 \cdot \mathrm{I} g$ hexose $/ 24 \mathrm{~h}$ for intestinal hydrolysis, but only in Expt 3 was there any appreciable digestion and this yielded less than $8.0 \mathrm{~g}$ carbohydrate. The digestion of cellulose and the pentose component of hemicellulose took place almost entirely in the stomachs. Again the nutritional importance of the pentosan is emphasized in that it accounts for more than $31 \%$ of the organic matter digested in the rumen.

\section{The passage of microbial carbohydrate into the duodenum}

The significance of microbial carbohydrate entering the intestines was examined in a goat. It is impossible to establish a complete physical separation of the microbial elements and the food residues, but reference to the monosaccharides present in the hydrolysates (Fig. 3) indicates the degree to which the carbohydrate from food residues included in the micro-organism fraction interferes with the analysis for microbial carbohydrate. Xylose is the main component in the hydrolysate of the fibre fraction derived from the hemicellulose, xylan. The amount of xylose accounted for as much as $18.0 \%$ of the dry matter of the fibre fraction but seldom exceeded $1.0 \%$ in the micro-organism fraction. On the other hand, the main monosaccharide produced by hydrolysis of the micro-organism fraction is glucose and this accounted for only approximately 10 \% of the monosaccharides in the hydrolysate of the fibre fraction. Thus, in view of the low xylose content of the micro-organism fraction, it seemed safe to assume that the glucose derived from fibre residues in the microorganism fraction is negligible.

The periodic variation in concentration of microbial carbohydrate passing into the duodenum is illustrated in Fig. 4 and compared with the carbohydrate assayed in the fibre fraction. Glucose will mainly be the hydrolysis product of the microbial storage polysaccharide identified and isolated by Oxford (195I). The time for the process of synthesis and storage of this polysaccharide to achieve its peak effect on the concentrate passing into the duodenum is some $3-4 \mathrm{~h}$ after feeding. Heald (I95 I) found a similar pattern of storage for micro-organisms in the rumen, but this does not necessarily reflect the transport into the intestines.

The concentration in duodenal contents of glucose due to the micro-organism fraction ranged from 6.1 to $45^{\circ} 6$ (mean $24^{\circ} 0$ ) $\mathrm{mg} / \mathrm{I} 00 \mathrm{ml}$, and the total carbohydrate subject to hydrolysis by $\mathrm{I} \cdot 5 \mathrm{~N}-\mathrm{H}_{2} \mathrm{SO}_{4}$ from $2 \mathrm{r} \cdot 5$ to $69 \cdot 3$ (mean $\left.48 \cdot 6\right) \mathrm{mg} / \mathrm{IoO} \mathrm{ml}$. This is only a small proportion of the carbohydrate entering the duodenum, even if cellulose is excluded, since the fibre fraction provides between $164^{.6}$ and 575.5 (mean $34 \mathrm{r}^{\circ}$ ) $\mathrm{mg} / \mathrm{r} 00 \mathrm{ml}$, almost $90 \%$ of which is in the form of pentosan. The variation in concentrations of carbohydrate present in the microbial fraction and the fibre fraction of the duodenal contents is shown in Fig. 4. 
The possibility that carbohydrate might have been released into the supernatant fluid as a result of the disruption of the micro-organisms by the processes in the omasum and abomasum was examined. The values for free polysaccharide were very low, ranging from 3.7 to 9.2 (mean $6 \cdot 9$ ) $\mathrm{mg} / 100 \mathrm{ml}$, the peak values appearing at the times when maximum microbial polysaccharide was entering the duodenum.
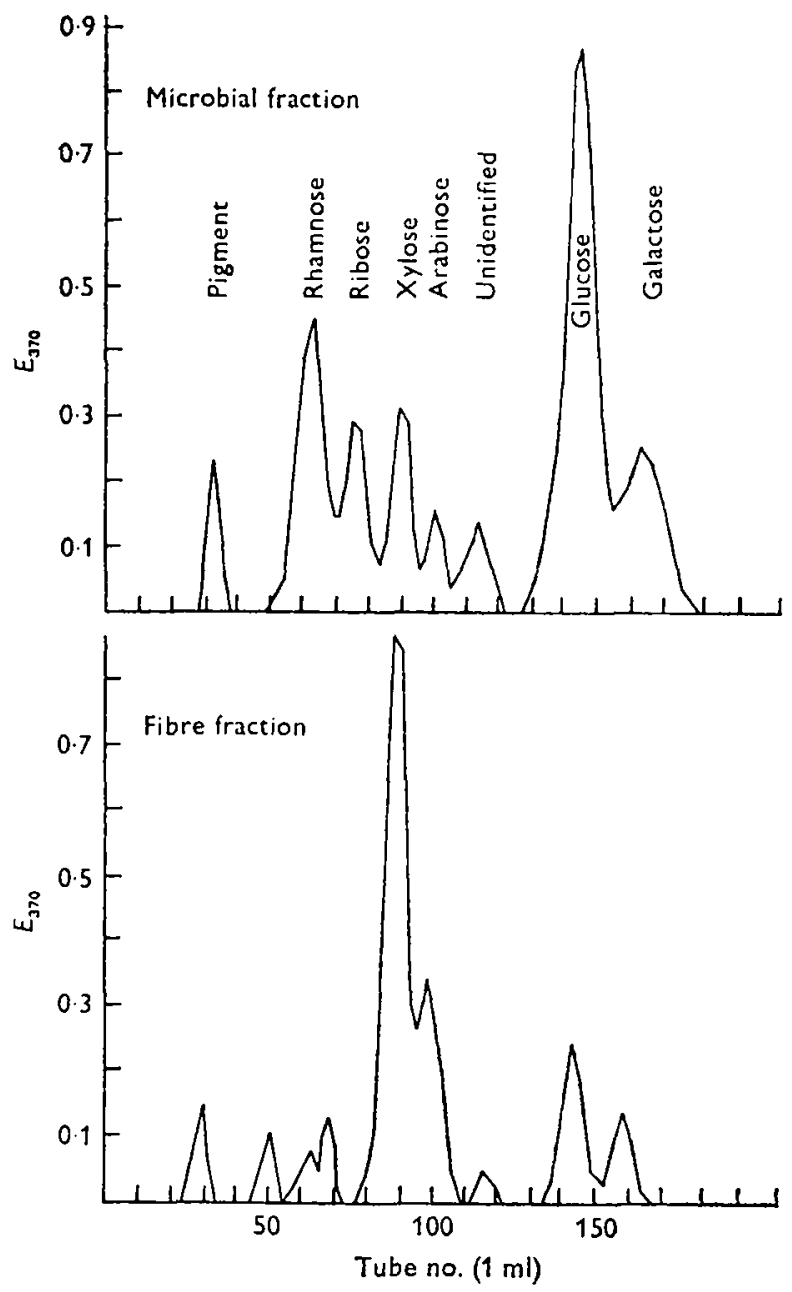

Fig. 3. Cellulose column chromatography of monosaccharides in the hydrolysates of microbial and fibre fractions from the duodenal contents of a goat.

The analyses for cellulose and carbohydrate in the fibre and microbial fractions from the goat are presented in the form of lignin ratios in Fig. 5. There was no measurable fraction in the faeces which could be compared with the microbial carbohydrate of the duodenal contents. The measurement of faecal carbohydrate is representative of the hemicellulose fraction of faeces, since there is no soluble component in the 'pectin' fraction to be accounted for. Similarly, the carbohydrate in the fibre 
fraction of duodenal contents is fairly representative of the hemicellulose fraction of duodenal contents, since only a small proportion of the pentosan appeared in the microbial fraction.

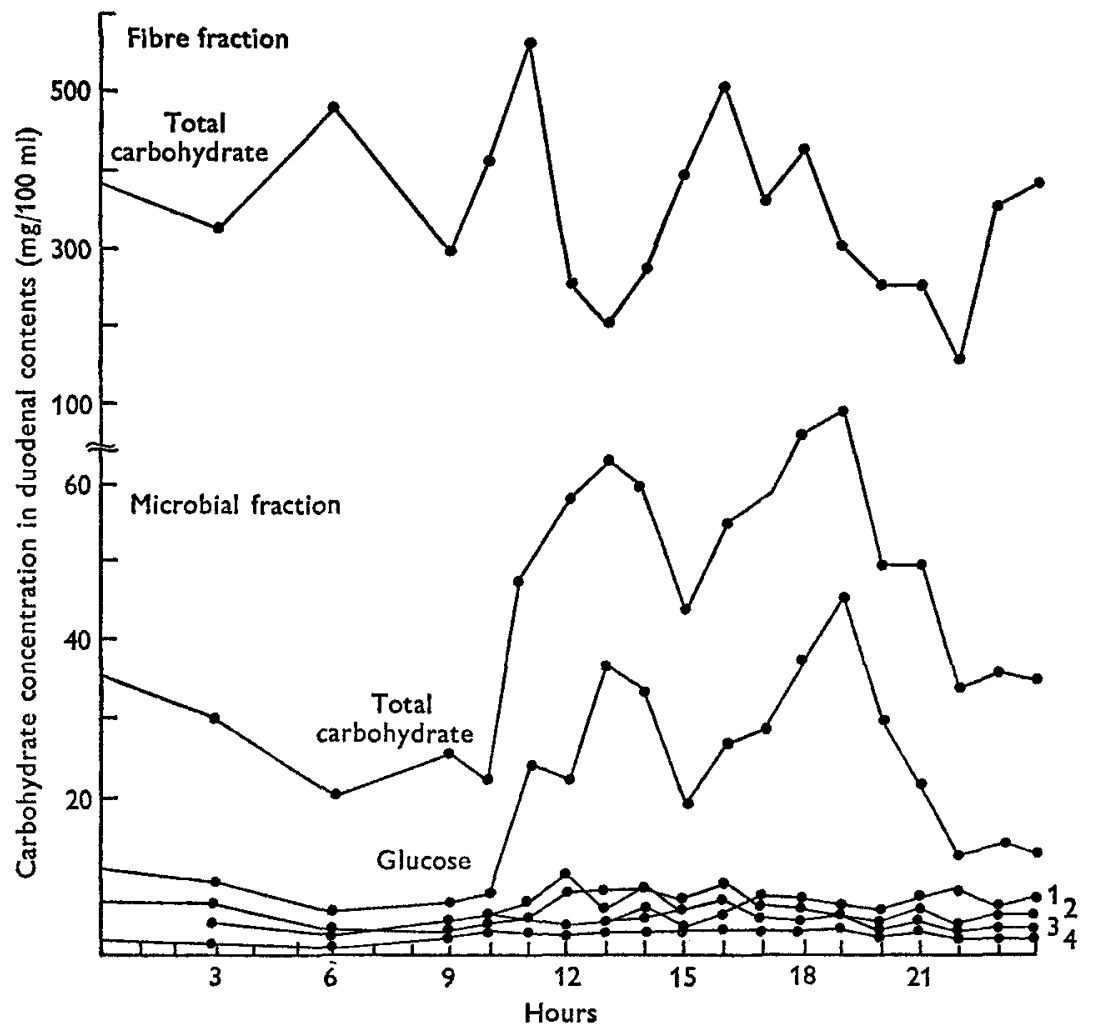

Fig. 4. Variation in concentrations of carbohydrate present in microbial and fibre fractions of duodenal contents of a goat. Curves $x, 2,3$ and 4 represent rhamnose, galactose, xylose and ribose respectively.

The mean values with their standard errors for the lignin ratios for cellulose, and for carbohydrate in the fibre and microbial fractions in the duodenum were $1 \cdot 37 \pm 0 \cdot 1 \mathrm{I}$, $0.78 \pm 0.09,0.10 \pm 0.03$ respectively for the assays illustrated in Fig. 5. The faecal lignin ratios for cellulose and hemicellulose were $I \cdot I 5$ and $0 \cdot 78$ respectively. The total excretion of lignin amounted to $6 \mathrm{I} \cdot 7 \mathrm{~g} / \mathrm{d}$. It is clear from these values that in this animal some cellulose was digested in the intestine. The lignin ratios for material entering the duodenum exceeded the faecal value at all times of the day. The pattern of change for fibre carbohydrate is comparable with that of cellulose, as was noted for hemicellulose in the experiments on the sheep, but there was no evidence of degradation in the intestine. The total digestion of the carbohydrate in the microbial fraction amounted to approximately $6 \mathrm{~g} / 24 \mathrm{~h}$ and glucose accounted for a little less than half of this.

The digestion of cellulose and total hydrolysable carbohydrate and organic matter in the goat are set out in Table 4 . The quantities passing through the duodenum are 
combined values for the microbial fraction and fibre fraction estimated from lignin ratios. These findings are very similar to those of the experiments with sheep presented in Tables $I$ and 3 .

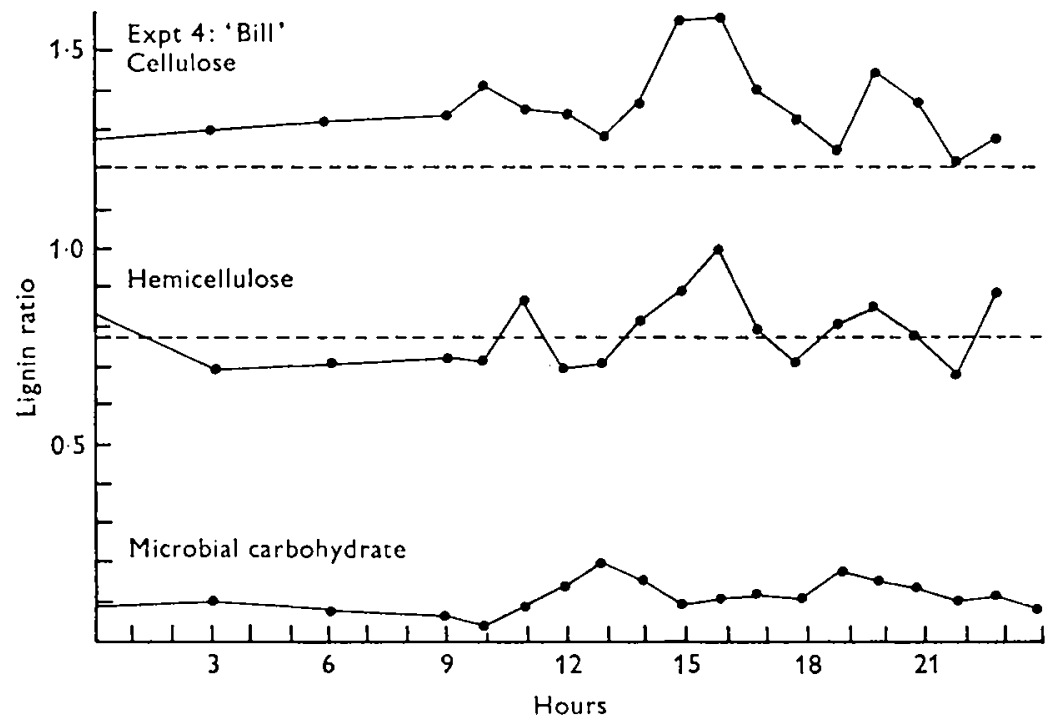

Fig. 5. Variation in lignin ratios of cellulose, fibre carbohydrate and microbial carbohydrate in duodenal contents of a goat. The faecal lignin ratios for cellulose and hemicellulose are shown as broken lines.

Table 4. Quantities of organic matter and of carbohydrate disappearing from stomach and intestines in a goat feeding on hay

\begin{tabular}{|c|c|c|c|c|c|c|c|}
\hline \multirow[b]{2}{*}{ Constituent } & \multirow[b]{2}{*}{$\begin{array}{l}\text { Hay } \\
(\mathrm{g} / 24 \mathrm{~h})\end{array}$} & \multirow{2}{*}{$\begin{array}{l}\text { Amount } \\
\text { passing } \\
\text { into } \\
\text { duodenum } \\
\text { (g/24 h) }\end{array}$} & \multirow[b]{2}{*}{$\begin{array}{l}\text { Faeces } \\
(\mathrm{g} / 24 \mathrm{~h})\end{array}$} & \multicolumn{2}{|c|}{ Amount digested } & \multicolumn{2}{|c|}{$\begin{array}{c}\begin{array}{c}\text { Amount digested } \\
\text { in stomach }\end{array} \\
\end{array}$} \\
\hline & & & & $g / 24 h$ & $\begin{array}{l}\text { Percentage } \\
\text { of amount } \\
\text { eaten }\end{array}$ & $g / 24 h$ & $\begin{array}{l}\text { Percentage } \\
\text { of total } \\
\text { digested }\end{array}$ \\
\hline Organic matter & 704 & $388 \cdot 2$ & $245^{\prime 2}$ & $458 \cdot 8$ & $65 \cdot 1$ & $385 \cdot 1$ & 83.9 \\
\hline Cellulose & $45 \mathrm{I}$ & 84.5 & 60.7 & 180.3 & $71 \cdot 8$ & $166 \cdot 5$ & $92 \cdot 4$ \\
\hline Carbohydrate pentose & 121 & $43 \cdot 5$ & $40 \cdot 6$ & 80.5 & $66 \cdot 5$ & $77 \cdot 6$ & $96 \cdot 4$ \\
\hline $\begin{array}{l}\text { Hexose released by } \\
\text { treatment with } \\
\text { r.5 N- } \mathrm{H}_{2} \mathrm{SO}_{4}\end{array}$ & $33 \cdot 6$ & 10.4 & $7 \cdot 6$ & 26.0 & $78 \cdot 8$ & $23 \cdot 2$ & $89 \cdot 2$ \\
\hline
\end{tabular}

\section{DISCUSSION}

Bondi \& Meyer (1943) found the digestibility of pentosans in sheep on a number of diets to be remarkably constant, ranging from $64 \cdot 0$ to $66 \cdot 2 \%$. Our experiments yielded similar values, between 58.0 and $68.4 \%$ of the dietary pentosan being digested, and providing $25-31 \%$ of the total digestible carbohydrate of the diet.

Most of the pentosan $(96.4-99.6 \%$ ) was digested in the stomachs. The amount which apparently disappeared from the intestines was no more than $3 \mathrm{~g} / 24 \mathrm{~h}$. The pentosanase activity in the rumen is associated with the microbial population (Howard, 1955, 1957), and Bryant (1959) has listed the types of organism which ferment xylose. 
The extent of digestion of pentosan in the stomach is very similar to that of cellulose, for which there was also very little evidence of intestinal degradation. It is possible that the microflora of the caecum and colon have less enzyme activity but more probable that the residual fibre polysaccharide is less susceptible to microbial attack after digestion in the rumen.

Gray $e$ t al. (1958) found that as little as $25 \%$ of the dietary pentosan was digested in the stomach of sheep feeding on hay. These observations were made on sheep slaughtered at intervals after feeding and calculations were made by use of the lignin ratio technique. In the studies described here the extent of digestion of pentosan in material passing into the duodenum varied considerably at different periods of the day, as indicated by the lignin ratio technique (Figs. 2, 5). However, the variation would never account for such a low apparent digestibility of pentosan from a single sample, and nearly all the measurements of Gray et al. were considerably lower than those recorded here. No observations of total digestion of pentosan were recorded by these authors, but if it was as much as in our experiments, or in those of Bondi \& Meyer (1948), it would appear that the large intestine would be required to play a considerable part in pentosan digestion.

The results of our experiments show that the total quantity of carbohydrate other than cellulose which entered the duodenum did not exceed $95 \mathrm{~g}$ in any of the experiments, and approximately $80 \%$ of this quantity was due to the hemicellulose, pentosan. Approximately $2 \mathrm{~g}$ digestible glucose $/ 24 \mathrm{~h}$ passed into the duodenum in the soluble 'pectin' fraction. This was probably microbial polysaccharide and not dietary pectin carbohydrate as evidenced by the comparative composition. The estimated quantity also closely matched the actual amount of microbial glucan passing into the duodenum of the goat. Obviously this cannot be considered to have any nutritional significance. The digestibility of the hexose component of the hemicellulose fraction was greater than that of the pentose component and a greater proportion was digested in the intestine. It is possible that any insoluble starch associated with the structural polysaccharide may account for this, and its ability to survive rumen fermentation would make it available for intestinal degradation where in one experiment it supplied almost $8 \mathrm{~g}$ of digestible hexose.

It should be emphasized that the observations of Ridges \& Singleton (1962) were made on animals receiving a hay diet supplemented with concentrates. In view of available evidence that very little dietary starch survives rumen fermentation (Weller \& Gray, 1954), it would appear that the intestinal digestion of such large amounts of carbohydrates might be explained in terms of pentosan. It seems possible that the efficiency of the rumen for the digestion of fibre polysaccharide might be lowered by the presence of more readily available carbohydrate, with the result that the microbial population of the caecum and colon could play a more important part. The ability of the intestine to compensate for poor rumen digestion and the availability of dietary starch for intestinal degradation will be examined in a later paper.

We are grateful to Miss R. Cook and Mr J. Stowell for technical assistance, and to the Agricultural Research Council for financial support. 


\section{REFERENCES}

Annison, E. F., Hill, K. J. \& Lewis, D. (1957). Biochem. F. 66, 592.

Arni, P. C. \& Percival, E. G. V. (195 I). F. chem. Soc. 2, 1822.

Baker, P. (1943). Ann. appl. Biol. 30, 230.

Bondi, A. H. \& Meyer, H. (1943). F. agric. Sci., Camb. 33, 123.

Bondi, A. H. \& Meyer, H. (1948). Biochem. F. 43, 248.

Bryant, M. P. (1959). Bact. Rev. 23, 125.

Gardell, S. (195I). Acta chem. scand. 5, ror I.

Gray, F. V., Pilgrim, A. F. \& Weller, R. A. (1958). Br. F. Nutr. r2, 404.

Heald, P. J. (195I). Br, F. Nutr. 5, 84 .

Howard, B. H. (1955). Biochem. F. 60, i.

Howard, B. H. (r957). Biochem. F. 67, 643.

MacRae, J. C. \& Armstrong, D. G. (1969). Br. F. Nutr. 23, 377.

Masson, F. M. \& Oxford, A. E. (1951). F. gen. Microbiol. 5, 664.

Oxford, A. E. (195r). F. gen. Microbiol. 5, 83.

Paloheimo, L., Mäkelä, A. \& Salo, M. L. (1955). Maataloust. Aikakausk. 27, 70.

Porter, P. \& Singleton, A. G. (1965). Biochem. F. 96, 59 P.

Porter, P. \& Singleton, A. G. (1966). F. Physiol., Lond. 186, 145 $P$.

Porter, P \& Singleton, A. G. (1971). Br. F. Nutr. 25, 3.

Ridges, A. P. \& Singleton, A. G. (1962). F. Physiol., Lond. r6r, I.

Schambye, P. (195I). Nord. VetMed. 3, 555.

Singleton, A. G. (1961). F. Physiol., Lond. r55, r34.

Topps, J. H., Kay, R. N. B. \& Goodall, E. D. (r968). Br. Y. Nutr. 22, 26 r.

Weller, R. A. \& Gray, F. V. (r954). F. exp. Biol. 3I, 40. 